\title{
Performance of AISI 316L-stainless steel foams towards the formation of graphene related nanomaterials by catalytic decomposition of methane at high temperature
}

\author{
F. Cazaña ${ }^{\text {a }}$, N. Latorre $^{\text {a }}$, P. Tarifa ${ }^{a}$, C.J. Royo ${ }^{\text {a }}$, V. Sebastián ${ }^{\text {a }}$, E. Romeo ${ }^{\text {a }}$, M.A. Centeno ${ }^{\text {b }}$, \\ A. Monzón ${ }^{\mathrm{a}, *}$ \\ ${ }^{a}$ Instituto de Nanociencia y Materiales de Aragón (INMA), CSIC-Universidad de Zaragoza, Zaragoza, 50018, Spain \\ ${ }^{\mathrm{b}}$ Instituto de Ciencia de Materiales de Sevilla (ICMS), CSIC-Universidad de Sevilla, Sevilla, 41092, Spain
}

\section{A R T I C L E I N F O}

\section{Keywords:}

Graphene related materials

Graphene

Few layer graphene

Stainless steel foam

Catalytic methane decomposition

Carburization

\begin{abstract}
A B S T R A C T
This work explores the preparation of graphene-related materials (GRMs) grown on stainless steel foams via catalytic decomposition of methane (CDM). The main active phases for the reaction are the Fe nanoparticles segregated from the stainless-steel after the activation stage of the foam. The effect of the feed composition and reaction temperature has been studied in order to maximize the productivity, stability and selectivity to GRMs. The maximum productivity attained was $0.116 \mathrm{~g} / \mathrm{g}_{\text {foam }} \mathrm{h}$ operating at $950{ }^{\circ} \mathrm{C}$ with a feed ratio of $\mathrm{CH}_{4} / \mathrm{H}_{2}=3$ (42.9\% $\% \mathrm{CH}_{4}: 14.3 \% \mathrm{H}_{2}$ ). The carbonaceous nanomaterials (CNMs) obtained were characterized by X-Ray diffraction, Raman spectroscopy and by transmission and scanning electron microscopy. The parameters of the kinetic model developed are directly related to the relevant stages of the process, including carburization, diffusion-precipitation and deactivation-regeneration. The balance among these sequential stages determines the overall performance of the activated foam. In conditions of rapid carburization of the Fe NPs $\left(\mathrm{p}_{\mathrm{CH} 4}>14 \%\right)$, the productivity to CNMs is favoured, avoiding an initial deactivation of the active sites by fouling with amorphous carbon. After a rapid carburization, the selectivity to the different CNMs is governed by the ratio $\mathrm{CH}_{4} / \mathrm{H}_{2}$, and mainly by the temperature. Thus, the formation of GRMs, mainly Few Layer Graphene (FLG) and even graphene, is favoured at temperatures above $900{ }^{\circ} \mathrm{C}$. At lower temperatures, carbon nanotubes are formed.
\end{abstract}

\section{Introduction}

During the last years, the production of carbonaceous nanomaterials (CNMs), such as nanotubes (CNTs), nanofibers (CNFs), GrapheneRelated Materials, graphite nanolayers, graphene nanoflakes, etc. is receiving a continuous industrial and scientific interest due to their extraordinary physical and chemical properties $[1,2]$. For these reasons, the use of carbonaceous nanomaterials is being intensively studied for a large number of potential applications such as electronics, sensors, photonics, biochemistry, energy storage, catalysts, etc. [3-8]. Regarding the application of these materials as catalyst, the carbonaceous nanomaterials can be used as catalyst supports, or even as catalysts themselves, in a wide range of processes $[9,10]$. However, the practical use of these catalysts in powered form presents important disadvantages. For example, large pressure drops or the necessity of a complex filtration and separation stage increase the capital investment, and hamper its industrial application [11].

A solution to avoid these operational problems is the use of structured catalysts as monoliths, foams or membranes, because the mass and heat transfer rates in these type of devices is significantly enhanced [12-16], and moreover the pressure drop is decreased, especially in the case of open foams $[17,18]$.

Besides, the costly and time-consuming filtration process after reaction is avoided, and the catalyst remains dispersed ensuring the accessibility to reactants [19]. However, a typical drawback of the structured reactors is that the active catalytic phase must be deposited over the external surface of the substrate. The method commonly used to carry out this stage is the washcoating of the substrate with a slurry containing the catalytic material. This step requires careful attention for complex geometries, as foams or cloths. For this reasons, it is quite difficult to produce long term stable and reproducible coatings [12,16, 20-22]. In order to overcome these problems, direct growth of the

\footnotetext{
* Corresponding author.

E-mail address: amonzon@unizar.es (A. Monzón).
} 
carbonaceous nanomaterials over metallic substrates takes advantage of the catalytic behaviour of their intrinsic components [23-26].

Among the current available technologies to produce CNMs, the catalytic chemical vapour decomposition (CCVD) of hydrocarbons (or $\mathrm{CO}$ ) is considered an attractive method due to its low-cost and easy scalability for mass production [27-29]. In this technique, transition metal catalyst nanoparticles are exposed to a gaseous carbon source, commonly a light hydrocarbon (e.g., $\mathrm{CH}_{4}, \mathrm{C}_{2} \mathrm{H}_{2}, \mathrm{C}_{2} \mathrm{H}_{4}$ ), at elevated temperatures $\left(600-1200{ }^{\circ} \mathrm{C}\right)$. It is decomposed into carbon atoms, which diffuse through the metal nanoparticles, and precipitate forming the carbonaceous nanomaterial. The growth of the carbonaceous material continues as long as the nanoparticles have active sites available on their surface for the hydrocarbon adsorption and decomposition, and there is a positive driving force for the migration and precipitation of the carbon atoms [30-32]. The most commonly used active metals for the hydrocarbon decomposition are $\mathrm{Fe}$, Co and $\mathrm{Ni}$, because of their high carbon solubility and high carbon diffusion rate at the usual reaction temperature [33]. In addition, other metals such as $\mathrm{Cu}, \mathrm{Pt}, \mathrm{Pd}, \mathrm{Mn}, \mathrm{Mo}$, $\mathrm{Cr}, \mathrm{Sn}, \mathrm{Au}, \mathrm{Mg}, \mathrm{Al}$ have also been used in this process, in order to modulate the carbon diffusivity and the final structure of the CNM produced [34-37]. Later, the separation and purification stages will determine the final structure and therefore the real applications in which these nanomaterials can be used.

Separately to the development of new applications, our goal is the maximization of the productivity and selectivity of CNMs growth process using structured metallic substrates. Stainless steel presents high content in $\mathrm{Fe}$ (and also $\mathrm{Ni}$ ), which makes it a quite appropriate candidate to be used as catalytic material for this purpose avoiding the need to deposit pre-shaped metal nanoparticles [38,39]. Once the substrate is selected, the aim is to optimize the formation of hybrid systems, composed by CNMs grown over structured metallic devices for their use, for example, as reactors in liquid-phase reactions (e.g. elimination of contaminants from wastewater, liquid phase hydrogenation, etc.).

The productivity, the type and the quality of the CNMs formed have been determined. Knowledge the reaction mechanism is crucial to properly control of the production of the CNMs. Based on this mechanism, our group has been working on the modelling of the kinetics of growth of CNMs [31-33,40-42], in order to quantify the influence of the reaction temperature and feed composition on the rate of carbon formation in the context of the reaction mechanism.

On the other side, given that methane is the hydrocarbon with the highest $\mathrm{H} / \mathrm{C}$ ratio, during their decomposition, the amount of hydrogen coproduced is the highest possible in comparison with other compounds. This fact supposes a clear advantage to easily integrate this process on the hydrogen economy roadmap. In addition, although nowadays the main origin of methane is still from fossil resources, the development of renewables routes for the production of biomethane (e.g. biogas from anaerobic fermentation of biomass and solid residues) is opening the sustainability of this process [43].

In a previous work [44], we studied the effect of the oxidation-reduction (activation) stage of a stainless steel foam, determining the optimal activation conditions. In this work, the influence of the reaction temperature and feed composition during the catalytic decomposition of methane (CDM) over stainless steel foams has been studied in order to maximize the productivity, stability and selectivity to the so-called Graphene Related Materials (GRMs). With the aim of specifically study the intrinsic kinetics of the material that forms the foam, stainless steel-AISI $316 \mathrm{~L}$, we have milled the foam to discount the effect of the complex hydrodynamics developed inside the channels. This result will be completed with the corresponding experiments using the unmodified foam in order to have the complete description of the catalytic performance of the foam.

\section{Experimental}

\subsection{Catalytic decomposition of methane}

The stainless steel foam used (AISI 316L) was supplied by Goodfellow ${ }^{\circledR}$ (www.goodfellow.com, ref: FE243825). First, the foam was cut in $10 \mathrm{~mm} \times 10 \mathrm{~mm}$ pieces to be placed inside a fixed bed reactor. Then, the samples were oxidized at $900{ }^{\circ} \mathrm{C}$ under $350 \mathrm{~N} \mathrm{ml} / \mathrm{min}$ of air and 350 $\mathrm{N} \mathrm{ml} / \mathrm{min}$ of $\mathrm{N}_{2}$. After this step, the foams were reduced in the same reactor at $900{ }^{\circ} \mathrm{C}$ using a flowrate of $700 \mathrm{~N} \mathrm{ml} / \mathrm{min}$ of a $50 / 50$ mixture of $\mathrm{H}_{2} / \mathrm{N}_{2}$. The treated foams were cooled to room temperature in an inert atmosphere. Finally, the samples were milled with an agate mortar and sieved to obtain a homogeneous particle size distribution. The range of size selected of the powdered particles of grinded was 80-140 micrometres to avoid internal diffusional restrictions. This stage is carried out in order to obtain the intrinsic reactivity of the stainless steel, avoiding the influence of the complex hydrodynamic flows developed inside the channels of the foam, coupled with the external mass transfer limitations. The performance of the entire structure of the foams in this reaction will be studied in future works, allowing to know the effects of the above mentioned phenomena.

The reaction was carried out at atmospheric pressure in a CI Precision's Thermogravimetric Analysis equipment (https://www.ciprecisi on.com/) operated as a differential reactor (i.e. methane conversions less than $5 \%$ ), and equipped with mass flow and temperature controllers. This experimental system allows continuous recording of the variations of sample weight and temperature during reaction. The reaction conditions were as follows: sample weight: $200 \mathrm{mg}$; total flow-rate: 700 $\mathrm{N} \mathrm{mL} / \mathrm{min}$.; temperature range: $800-950{ }^{\circ} \mathrm{C}$; feed composition range: $\%$ $\mathrm{CH}_{4}$ : from $3.6 \%$ to $42.9 \%, \mathrm{H}_{2}$ : from $0 \%$ to $42.9 \%$ and $\mathrm{N}_{2}$ until balance. After reaction, the sample is cooled down under $\mathrm{H}_{2} / \mathrm{N}_{2}$ atmosphere (50/50) till attaining $100{ }^{\circ} \mathrm{C}$, and the final step till room temperature using only nitrogen. The samples are stored at room temperature under $\mathrm{N} 2$ atmosphere, till their characterization.

\subsection{Stainless steel foam and carbonaceous nanomaterials characterization}

The bulk chemical composition of the foam was measured by atomic absorption in a VARIAN spectrophotometer (model SPECTRAA 110).

The X-ray diffraction (XRD) patterns were recorded within the range of $10-90^{\circ}(2 \theta)$ with a Rigaku D/Max 2500 apparatus operated at $3.2 \mathrm{~kW}$ $(40 \mathrm{kV}, 80 \mathrm{~mA})$ and with a rotatory anode of $\mathrm{Cu}$ using $\mathrm{Cu} \mathrm{K}_{\alpha}$ radiation.

Transmission electron microscopy (TEM) micrograph images were recorded in a FEI Tecnai T-20 microscope, operated at $200 \mathrm{kV}$. Scanning electron microscopy (SEM) micrograph images were captured in a FEI Inspect F50 microscope, operated at $10 \mathrm{kV}$. The carbonaceous nature of the materials formed during the reaction was characterized by Raman spectroscopy using a WiTec Alpha300 Confocal Raman Microscope, with a $532 \mathrm{~nm}$ laser excitation beam.

\subsection{Kinetic modelling of carbonaceous nanomaterials growth}

As it has been mentioned above, the influence of the operating conditions on the CNMs growth kinetics was previously studied in previous works [31-33,41,42,44]. Briefly, for the present case, the kinetic model considers the following main steps: i) adsorption and decomposition of $\mathrm{CH}_{4}$ molecules on the metal nanoparticles segregated during the activation stage to the external surface of the stainless steel substrate $[44,45]$; ii) formation of a metastable metallic carbide which decomposes into carbon atoms at the metal carbide-metal nanoparticle interface; iii) diffusion of these carbon atoms through the metal nanoparticle and subsequent carbon precipitation at the metal-support interface; iv) formation and growth of the carbonaceous nanomaterial, whose nature (e.g. nanotubes, nanofibers, graphite) depends on the operating conditions and on the catalyst composition; v) carbon growth 
termination due to catalyst deactivation or by the effect of steric hindrance of the nanomaterial grown. The kinetic parameters involved on the CNMs growth were estimated from the curves of carbon concentration, $m_{C}\left(g_{C} / g_{\text {foam }}\right)$ vs. time, Figs. $3 \mathrm{a}$, b and 7 , obtained at the different operating conditions studied.

\subsubsection{Kinetic model for carbon growth on stainless steel foams}

The kinetic model used in this study has been presented and discussed in previous contributions of our group [32,33,42,44-46]. Here we present a brief description of the application of the model to this specific case. According to the reaction mechanism described above, in absence of any steric hindrance phenomena, the rate of carbon formation over the activated foam is consequence of the following consecutive phenomena: i) carburization of Fe nanoparticles, expressed in terms of degree of carburization $\theta_{S}(t)$; ii) diffusion of the $\mathrm{C}$ atoms through the $\mathrm{Fe}$ nanoparticles, expressed in terms of intrinsic rate of carbon formation, $j_{C O}$, and iii) eventual deactivation of these Fe nanoparticles, determined by the residual activity, $a(t)$. The coupling of these phenomena can be expressed as follows $[32,42,46]$ :

$r_{C}(t)=\left(\frac{d m_{C}}{d t}\right)_{t}=\left(r_{C}\right)_{0}(t) \cdot a(t)=j_{C_{0}} \cdot \theta_{S}(t) \cdot a(t)$

In this equation, $r_{C}(t)$ represents the rate of carbon formation over the catalysts and $\left(r_{C}\right)_{0}(t)$ is the rate of carbon formation in absence of any deactivation phenomena $[32,46]$. This rate varies along time due to the progressive carburization of the Fe nanoparticles during the reaction. The term $j_{C O}$ represents the intrinsic carbon growth rate for the fresh catalyst, and it is directly related to the diffusion of the carbon atoms leaved on the Fe NPs after the methane adsorption and decomposition over their surface. The term $\theta_{S}(t)$ is the degree of carburization of the surface of the metallic Fe nanoparticles segregated on the foam surface after the activation step. Finally, the term $a(t)$ is the remaining catalyst activity of these Fe nanoparticles, defined as the ratio between reaction rate at a given time and the reaction rate of the fresh catalyst.

In this mechanism of carbon formation, a key step is the formation of a metastable surface carbide [47], which in the cyclic process of formation-decomposition introduces the carbon atoms inside the metallic nanoparticles $[47,48]$. As a consequence of this initial stage of surface carburization, there is a delay on the carbon growth responsible of the appearance of a period of induction, in which the reaction rate is very low. This period is characterized by the sigmoidal shape of the $m_{C}$ vs. time curves, see Fig. 3 for example. In the present case, we have assumed that the carburization process follows an autocatalytic kinetics, according to the following expressions [32,46]:

$$
\begin{aligned}
& r_{S}=\frac{d \theta_{S}}{d t}=\psi_{S} \cdot\left(1+K_{S} \cdot \theta_{S}\right) \cdot\left(1-\theta_{S}\right) \leftrightarrow \theta_{S}=\frac{1-\exp \left(-\psi_{C} \cdot t\right)}{1+K_{S} \cdot \exp \left(-\psi_{C} \cdot t\right)} \\
& \psi_{C}=\psi_{S} \cdot\left(1+K_{S}\right)
\end{aligned}
$$

In the above equations, the term $\psi_{S}$ represents the intrinsic rate of carburization and $K_{S}$ is a parameter that modulates the autocatalytic effect of the carbide formed [32].

As regards to the catalyst deactivation, if the diffusion rate of $\mathrm{C}$ atoms is not high enough, the accumulation of non-structured carbon over the surface of Fe NPs causes the decrease in the number of accessible sites and therefore the activity decays. Furthermore, in Figs. 3a, b, and 7, it can be seen the presence of a residual reaction rate at the end of the experiment. This residual activity is consequence of the partial gasification of the carbonaceous deposits by the hydrogen generated during the reaction [40,42]. Consequently, we have used the Deactivation Model with Residual Activity (DMRA) [49-52] in order to take into account this experimental result. The simplest case on the DMRA model can be expressed as follows [52]:

$$
-\frac{d a}{d t}=\psi_{d} \cdot a-\psi_{r} \cdot(1-a) \quad \leftrightarrow \quad a=\frac{\psi_{r}}{\psi_{G}}+\frac{\psi_{d}}{\psi_{G}} \cdot \exp \left(-\psi_{G} \cdot t\right)
$$$$
\psi_{G}=\psi_{d}+\psi_{r}
$$

In the above equation, the terms $\psi_{d}$ and $\psi_{r}$ are the intrinsic kinetic rates of deactivation and regeneration respectively.

Finally, the combination of Eqs. (1)-(3) allows the calculation of the evolution along time of mass of carbon formed during the decomposition of methane. The expression obtained is given by:

$m_{C}=\frac{j_{C_{0}}}{\psi_{G}} \cdot \int_{0}^{t} \frac{\left(1-\exp \left(-\psi_{C} \cdot t\right)\right) \cdot\left(\psi_{r}+\psi_{d} \cdot \exp \left(-\psi_{G} \cdot t\right)\right)}{\left(1+K_{S} \cdot \exp \left(-\psi_{C} \cdot t\right)\right)} \cdot d t$

This equation requires numerical integration and contains five parameters, all of them related to the main steps of the mechanism. Thus, $j_{C O}$ is related with intrinsic rate of diffusion of carbon atoms, $\psi_{S}$ and $K_{S}$ are associated to the carburization step; and $\psi_{d}$ and $\psi_{r}$ are linked to the catalyst deactivation. These parameters can be estimated by non-linear least-squares multivariable regression of the experimental $m_{C}$ vs. time data presented in Figs. 3 and 7. The objective function maximized is the Model Selection Criterion (MSC) [53], defined as:

$M S C=\ln \left(\frac{S S T}{S S R}\right)-\frac{2 \cdot p}{n_{p}-p}$

Where the terms SST and SSR are the sum of squared totals and squared residuals, calculated as follows:

$$
\begin{aligned}
& S S T=\sum_{i=1}^{n_{p}}\left(m_{C, \exp }-\overline{m_{C, \exp }}\right)^{2} \quad ; \quad S S R=\sum_{i=1}^{n_{p}}\left(m_{C, \exp }-m_{C, \text { cal }}\right)^{2} \\
& \overline{m_{C, \exp }}=\sum_{i=1}^{n_{p}} m_{C, \exp } / n_{p}
\end{aligned}
$$

In the above expressions $p$ is the number of fitting parameters and $n_{p}$ is the number of experimental points of each curve.

\section{Results and discussion}

\subsection{Stainless steel foam characterization before reaction}

The bulk composition of the stainless steel foam determined by atomic absorption is presented in Table 1 . As mentioned above, the presence of large amounts of Fe (ca. $70 \%$ ) and Ni (ca. $10 \%$ ) allows to the foam be used as a suitable catalyst to carry out the reaction of methane decomposition. After activation, the surface analysis by SEMEDX of the foam confirms the enrichment on $\mathrm{Fe}, \mathrm{Cr}$ and $\mathrm{Ni}$ of the surface, results not shown here. Thus, the atomic composition of the main metals was: $76 \%$ of $\mathrm{Fe}, 10 \%$ of $\mathrm{Cr}$ and $5,3 \%$ of $\mathrm{Ni}$ [45].

Fig. 1 shows the SEM and TEM images of the stainless steel foam after oxidation and reduction steps. As can be seen by SEM (Fig. 1a), activation stages cause some fractures and roughness in the stainless steel foam surface exposing the active metallic nanoparticles. However, the surface area of the grinded foam is also less than $1 \mathrm{~m}^{2} / \mathrm{g}$, similar to the value measured for the original foam, hence the activation and grinding steps do not modify this property.

In addition, TEM image (Fig. 1b) shows large amount of metal nanoparticles with high particle diameter $(>30 \mathrm{~nm}$ ), which a priori favours the formation of graphene-related materials at high reaction

Table 1

Composition of the stainless steel AISI $316 \mathrm{~L}$ foam by atomic absorption.

\begin{tabular}{llllll}
\hline$\% \mathrm{Fe}$ & $\% \mathrm{Cr}$ & $\% \mathrm{Ni}$ & $\% \mathrm{Mn}$ & $\% \mathrm{Mo}$ & $\% \mathrm{C}$ \\
\hline 70.4 & 13.6 & 10.8 & 1.44 & n.d. & n.d. \\
\hline
\end{tabular}



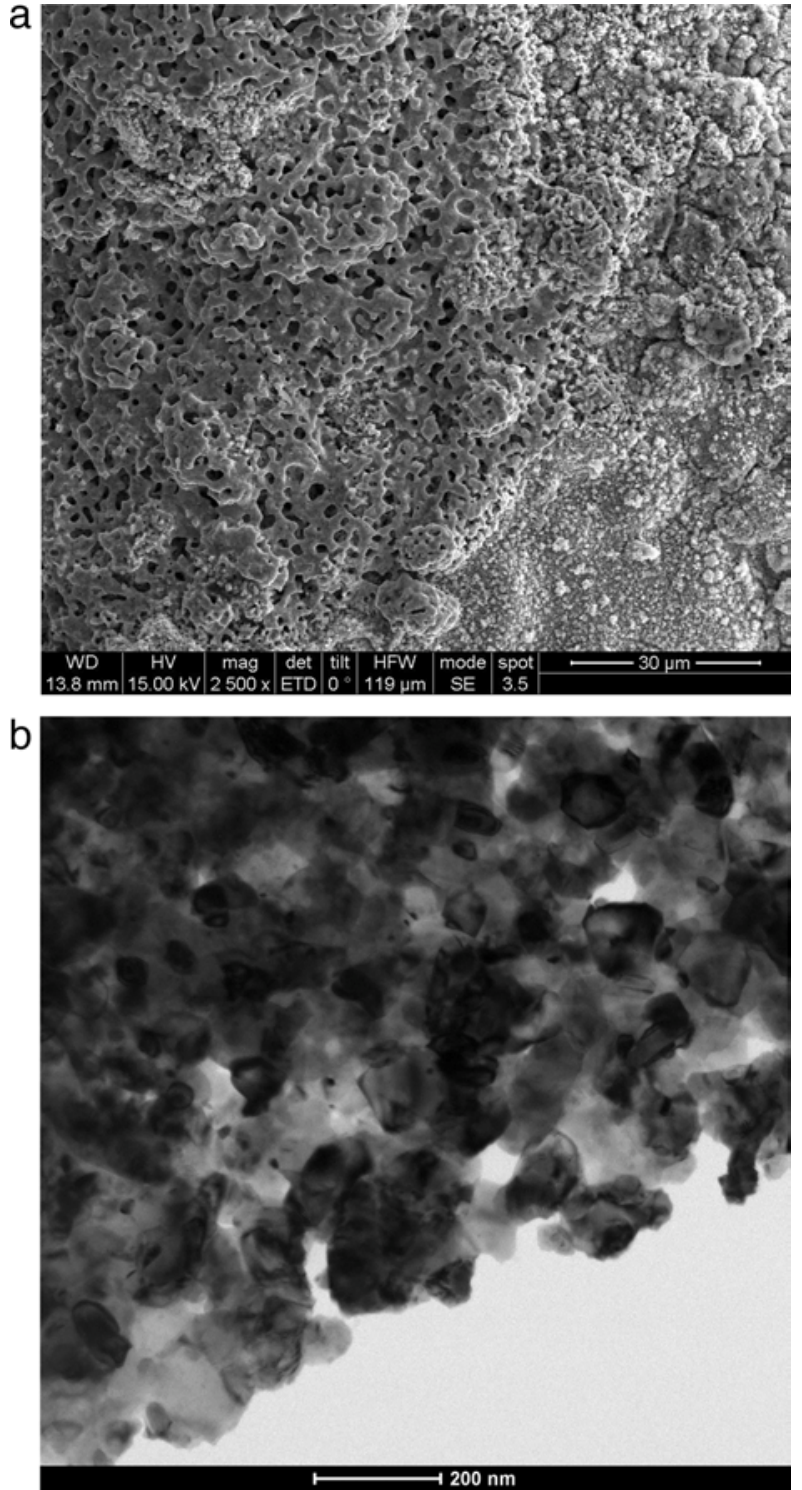

Fig. 1. a) SEM and b) TEM images of stainless steel foam after oxidation and reduction stages.

temperatures [33].

Finally, Fig. 2 shows the XRD patterns of the stainless steel foam after oxidation and reduction steps, i.e. just before reaction. In addition, in this Figure are included the XRD results after the several operating conditions studied. The pattern of the sample before reaction, black line, indicates that the foam is mainly formed by iron in metallic state (Code 01-080-3816), austenite phase (Code 00-033-0397) and mixed oxides, mainly $\left(\mathrm{Fe}_{0.6} \mathrm{Cr}_{0.4}\right)_{2} \mathrm{O}_{3}$ (Code 00-034-0412) and $\mathrm{Fe}_{2} \mathrm{O}_{3}$ (Code 00-0391346). The formation of these phases is consequence of the activation treatment of the foam before reaction [54].

\subsection{Catalytic decomposition of methane}

\subsubsection{Influence of the feed composition}

The effect of the partial pressure of methane on the productivity and on the quality of the graphene-related materials grown was further evaluated varying the methane concentration from $3.6 \%$ to $42.9 \%$, setting the hydrogen content at $14.3 \%\left(\mathrm{~N}_{2}\right.$ as gas balance, total flow rate $700 \mathrm{~N} \mathrm{~mL} / \mathrm{min}$ ). All the experiments were conducted at $950{ }^{\circ} \mathrm{C}$ due to the activity and high selectivity towards the formation of graphenerelated materials (GRMs) of the stainless steel occurs at this elevated
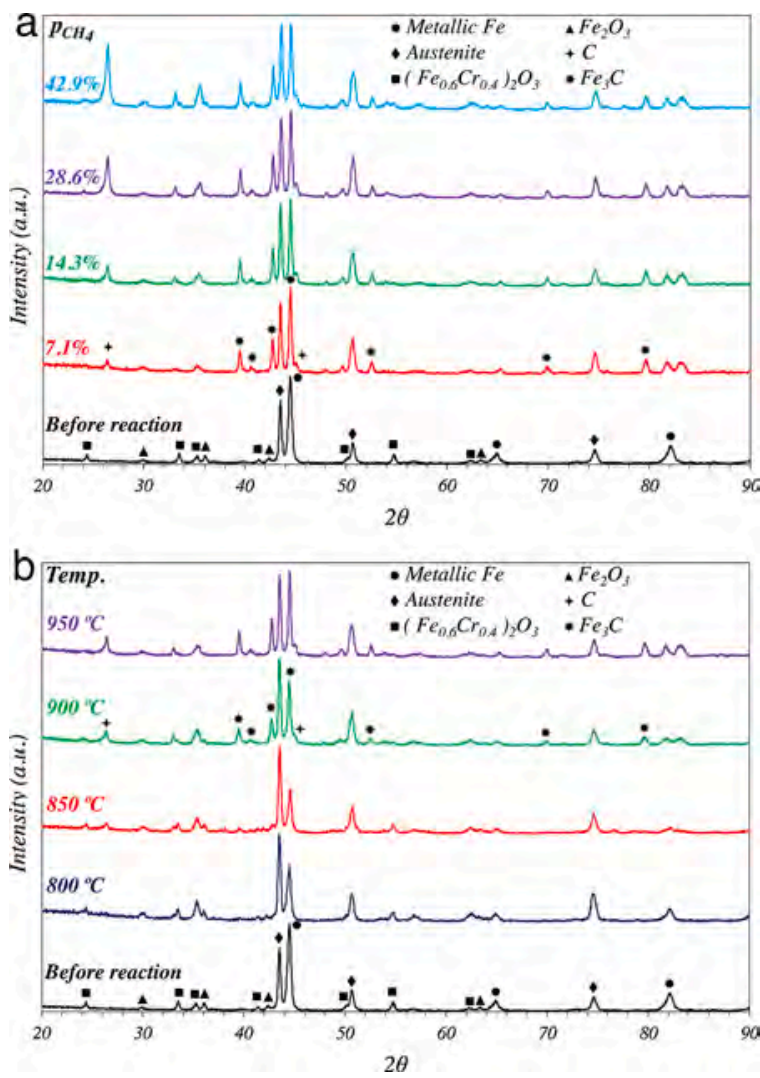

Fig. 2. XRD pattern of stainless steel foam after reaction. a) Influence of the partial pressure of methane @ $950{ }^{\circ} \mathrm{C}, 14.3 \% \mathrm{H}_{2}$, b) Influence of the reaction temperature@14.3\% $\mathrm{CH}_{4}, 14.3 \% \mathrm{H}_{2}$.

temperature [45].

The potential formation of soot by gas phase methane pyrolysis must always be considered in this reaction. In order to evaluate the contribution of the non-catalytic formation of carbon soot, we have made experiments using the bare $\mathrm{Cu}$ basket where the sample is placed, and after $2 \mathrm{~h}$ it was not observed any deposition of carbon at all the reaction conditions used.

Fig. 3a shows the carbon growth (left), and reaction rate (right) evolution over time, at different partial pressures of methane. In addition, the curves (dashed red lines) obtained after fitting with the kinetic growth model (Eq. (4)) are drawn in the figure.

The increase of methane content in the feed boosts the reaction rate increasing almost linearly the average productivity of the sample, see Table 2. Thus, the increment in methane concentration promotes the carburization of the exposed surface of the metal nanoparticles, increasing the number of carbon atoms formed and dissolved in the NPs. This fact favours the migration and finally the carbon precipitation at the metal-support interface [33]. In this case, the maximum productivity, $0.115 \mathrm{gC} /$ gfoam $\mathrm{h}$, was reached using a feed composition of $42.9 \%$ $\mathrm{CH}_{4}: 14.3 \% \mathrm{H}_{2}: 42.9 \% \mathrm{~N}_{2}$, Table 2 .

The evolution of the curves in Fig. 3 shows the presence of a maximum value of the reaction rate, see Fig. 3a right, which position and intensity depends on the operating conditions. The initial period corresponds to an induction period where the values of carbon concentration attained are keep quite low, see Fig. 3a left. After the maximum, the growth rate decreases continuously till attaining a residual value. The induction period is clearly appreciated at concentrations of methane below $14 \%$ in this case. Thus, for the experiment at 3.6 $\%$ of $\mathrm{CH}_{4}$, the maximum rate appears at around $25 \mathrm{~min}$ of reaction, attaining a value of $0.64 \cdot 10^{-3} \mathrm{gC} / \mathrm{gfoam}$ min and for the case of $7.1 \%$ of $\mathrm{CH}_{4}$, the maximum rate obtained, at $8 \mathrm{~min}$ of reaction, is $1.94 \cdot 10^{-3} \mathrm{gC}$ / gfoam min. At higher methane concentrations, above $14 \%$, the 

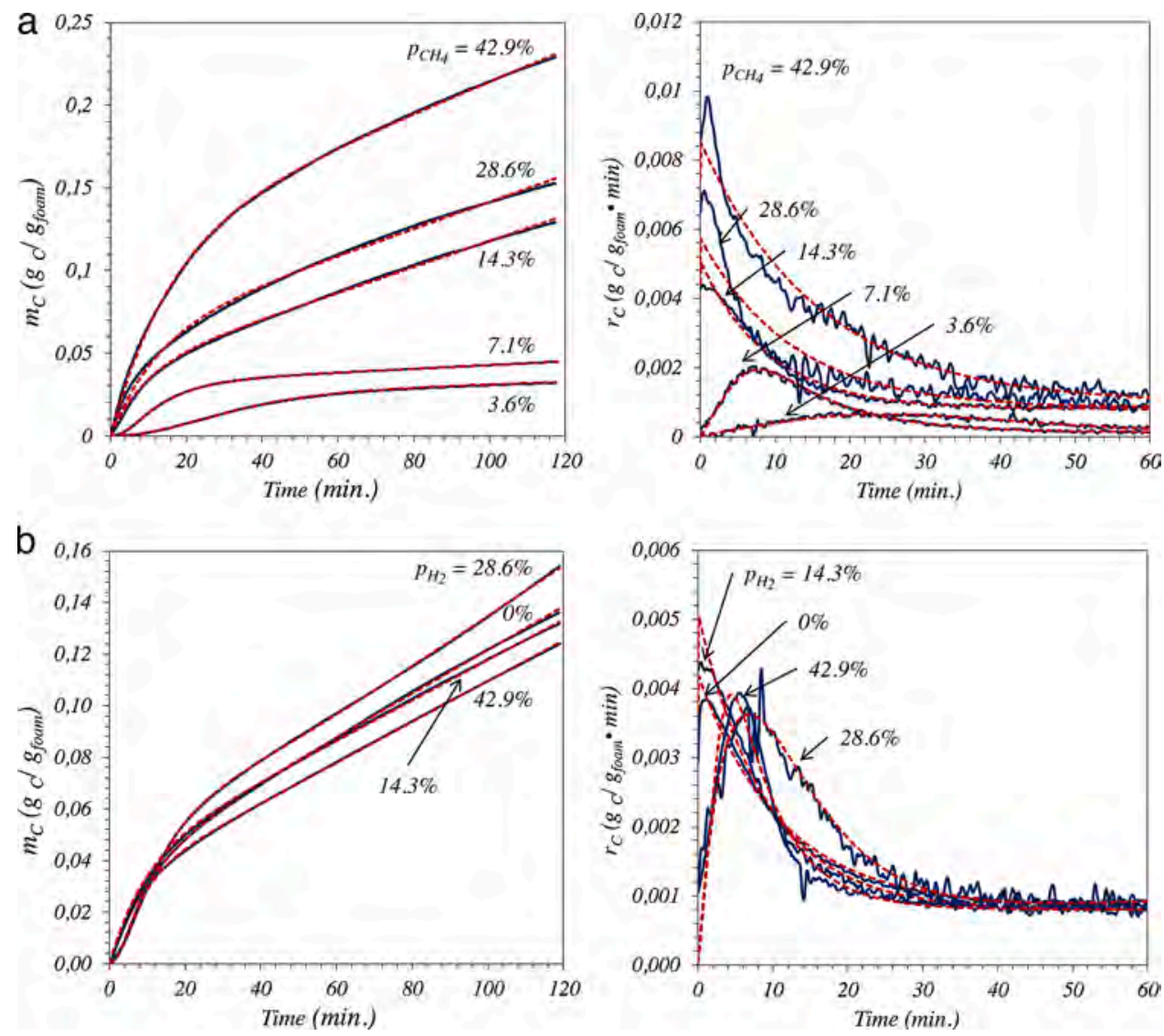

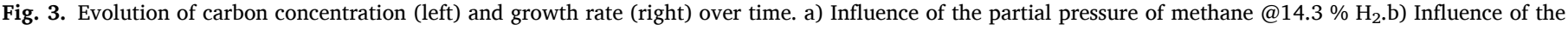

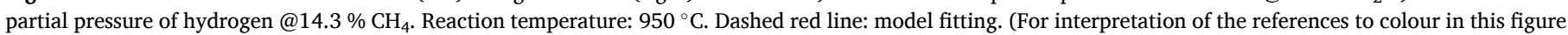
legend, the reader is referred to the web version of this article.)

Table 2

Effect of the partial pressure of methane over the kinetic parameters $j_{C O}, K_{s}, \psi_{S}, \psi_{d}$, and $\psi_{r}$.

\begin{tabular}{|c|c|c|c|c|c|c|}
\hline$\% \mathrm{CH}_{4}$ & $\mathrm{j}_{\mathrm{C} 0} \cdot 10^{3}\left(\mathrm{~g}_{\mathrm{C}} / \mathrm{g}_{\text {foam }} \min \right.$ & $\mathrm{K}_{\mathrm{S}}(-)$ & $\Psi_{\mathrm{S}} \cdot 10^{2}\left(\mathrm{~min}^{-1}\right)$ & $\Psi_{\mathrm{d}} \cdot 10^{2}\left(\mathrm{~min}^{-1}\right)$ & $\Psi_{\mathrm{r}} \cdot 10^{2}\left(\mathrm{~min}^{-1}\right)$ & Average Productivity $\cdot 10^{2}\left(\mathrm{~g}_{\mathrm{C}} / \mathrm{g}_{\text {foam. } \mathrm{h}}\right)$ \\
\hline 3.6 & $4.1 \pm 0.012$ & $9.19 \pm 0.18$ & $1.06 \pm 0.02$ & $5.28 \pm 0.06$ & $0.09 \pm 0.001$ & 1.62 \\
\hline 7.1 & $5.4 \pm 0.011$ & $5.29 \pm 0.05$ & $6.21 \pm 0.02$ & $9.81 \pm 0.01$ & $0.21 \pm 0.001$ & 2.24 \\
\hline 14.3 & $5.1 \pm 0.014$ & 0.0005 & 60340 & $9.25 \pm 0.04$ & $1.68 \pm 0.001$ & 6.57 \\
\hline 28.6 & $5.8 \pm 0.012$ & 0.0005 & 60340 & $7.05 \pm 0.09$ & $1.16 \pm 0.01$ & 7.69 \\
\hline 42.9 & $8.5 \pm 0.013$ & 0.0005 & 60340 & $5.66 \pm 0.02$ & $0.71 \pm 0.003$ & 11.52 \\
\hline
\end{tabular}

maximum rate already appears at the beginning of the reaction and the induction period is not detectable. The appearance of an induction period is a direct consequence of the existence of the initial carburization stage, so that the slower the carburization stage, the longer the induction period. On the contrary, a rapid carburization favours the CNMs growth, increasing the reaction rate. According to proposed model, Eq. (2), the kinetics of the carburization stage is determined by the parameters $\psi_{S}$ and $K_{S}$ [32].

On the other side, after the point of maximum reaction rate, the observed decay of the foam activity can be attributed to the combination of several complex factors including the fouling of the metal nanoparticles surface with amorphous coke, the decreasing of the $\mathrm{CH}_{4}$ diffusivity through graphite nanolayers covering the nanoparticles and the reconstruction and sintering of the metal nanoparticles [42]. All of these factors will affect the deactivation parameters of the DMRA. The residual rate observed is consequence of the partial regeneration of the fouled metallic NPs with the hydrogen present at the reaction.

Table 2 shows the dependence of the kinetic parameters with respect to the partial pressure of methane in the feed. The fitting obtained in all cases studied was excellent, as indicate the high values of the Model Selection Criterion (MSC > 6.6), of the Coefficient of Correlation $\left(\mathrm{R}^{2}>\right.$
0.999), and the low standard error determined for each parameter. As expected, the increase in the methane partial pressure enhances the intrinsic rate of carbon formation, given by $j_{C O}$. At high methane concentrations there are more carbon atoms available at the surface, and therefore the carbon flux is enhanced, rising the carbon productivity of the foam. In addition, the parameter $\psi_{S}$ increases with the partial pressure of methane, meanwhile the parameter $K_{S}$ decreases. The combined variation of $K_{S}$ and $\psi_{S}$ when the partial pressure of methane increases, explains the reduction of the initial induction period observed, Fig. 3a, disappearing at $\% \mathrm{CH}_{4}$ higher than $14.3 \%$. Above this critical concentration of methane, the carburization step is very fast, and it can be assumed that the degree of carburization of the metallic NPs, Eq. (2), is equal to 1 already from the beginning of the reaction.

Additionally, another interesting result is that the deactivation pattern of the catalytic material is different at each side of the critical value. At low partial pressures of methane, a low formation of carbon is observed. In these conditions, the carburization step is slow favouring the formation of fouling carbon, which avoid the adsorption and decomposition of the molecules of methane, and consequently the subsequent diffusion-precipitation step. On the contrary, at $\% \mathrm{CH}_{4}$ above $14 \%$, the rates of carbon formation are higher and the deactivation is 
less intense, Fig. 3a. In this situation, the diffusion-precipitation of the carbon atoms occurs before the total fouling of the metallic nanoparticles, attaining higher reaction rates. The calculated values of the parameters $\psi_{d}$ and $\psi_{r}$, presented in Table 2 are in agreement with the above discussion. Thus, the higher productivity attained at $\% \mathrm{CH}_{4}$ above $14 \%$ is consequence of the combination of a very quick carburization (low $K_{S}$ and high $\psi_{S}$ ), which favours the diffusion-precipitation rate (high $j_{C O}$ ), and a good balance of the $\psi_{d} / \psi_{r}$ ratio.

Fig. 2a shows the XRD acquired after reaction at $950{ }^{\circ} \mathrm{C}$ for the different partial pressures of methane studied. The main phases detected in these conditions are carbon (Code 00-041-1487), austenite (Code 00033-0397) and $\mathrm{Fe}_{3} \mathrm{C}$ (Code 00-034-0001), disappearing the metallic $\mathrm{Fe}$ phase present before reaction. In addition, the relative intensities of the carbon and the austenite phases increase with the partial pressure of methane. These results are in agreement with the proposed mechanism of carbon formation, which assumes that an increase in methane concentration favours the carburization of the Fe NPs, increasing the number of carbon atoms dissolved in them, favouring the carbon diffusion-precipitation at the metal-support interface [33].

The effect of the methane partial pressure on the quality of the CNMs grown was studied by Raman spectroscopy and the results are shown in Fig. 4a. The spectra obtained show the typical bands associated to the carbonaceous nanomaterials, which are identified as $\mathrm{D}\left(\sim 1350 \mathrm{~cm}^{-1}\right), \mathrm{G}$ $\left(\sim 1580 \mathrm{~cm}^{-1}\right)$, and $2 \mathrm{D}\left(\sim 2690 \mathrm{~cm}^{-1}\right)$ bands. The intensities ratio $\mathrm{I}_{\mathrm{G}} / \mathrm{I}_{\mathrm{D}}$ was used as an estimation of the relative number of defects present on the CNMs formed. Thus, an increase in $\mathrm{I}_{\mathrm{G}} / \mathrm{I}_{\mathrm{D}}$ ratio means a loss of the $\mathrm{C}$ $\mathrm{sp}^{2}$ aromaticity in the graphitic $\mathrm{C}-\mathrm{C}$ rings due to defects-induced $\mathrm{C} \mathrm{sp}{ }^{3}$ hybridization [55]. This also implies a decrease in the in-plane crystallite size $\left(L_{a}\right)$ of the carbonaceous nanomaterials obtained [56]. On the other hand, the $\mathrm{I}_{2 \mathrm{D}} / \mathrm{I}_{\mathrm{G}}$ ratio is associated to the number of graphene
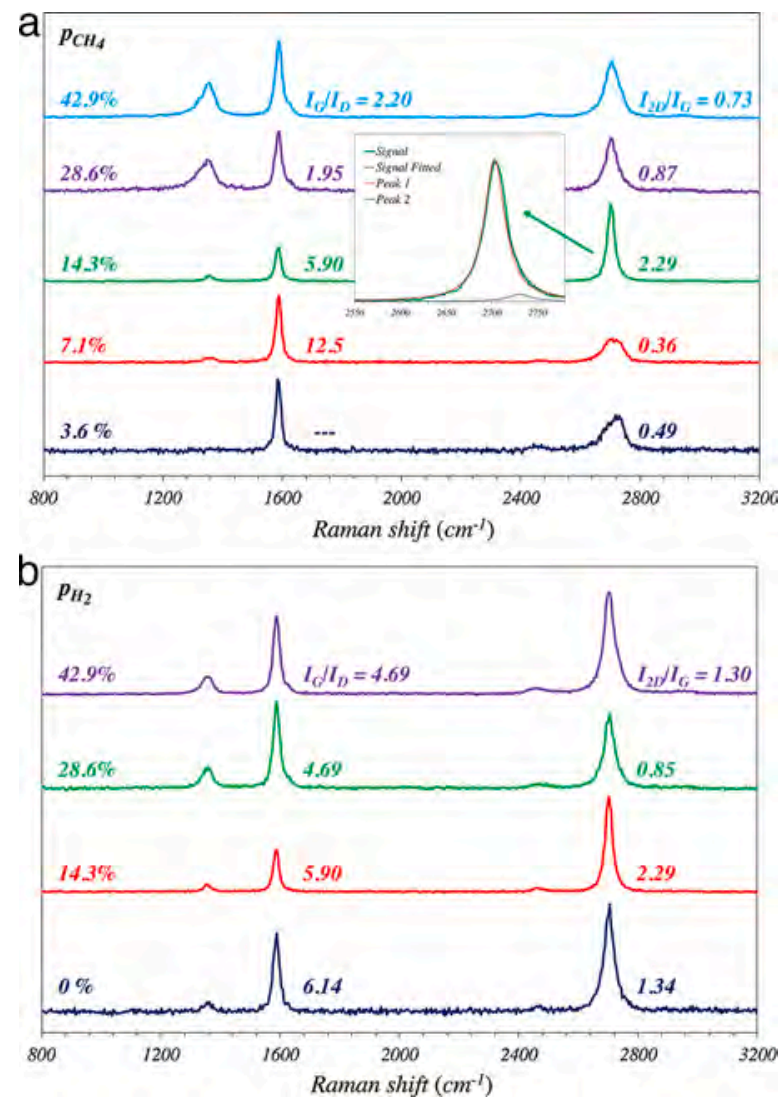

Fig. 4. Raman spectra obtained after reaction at $950{ }^{\circ} \mathrm{C}$. a) Influence of the partial pressure of methane @ $14.3 \% \mathrm{H}_{2}$.b) Influence of the partial pressure of hydrogen @14.3\% $\mathrm{CH}_{4}$. Inset: Deconvolution of 2D peak of the sample prepared at $950{ }^{\circ} \mathrm{C} @ 14.3 \% \mathrm{CH}_{4}$ and @14.3\% $\mathrm{H}_{2}$. layers presented on the graphenic-like material obtained [57-59].

In this case, it is observed that the increment in the methane concentration causes an increase in the intensity of the D band (Fig. 4a) indicating the formation of more defective amorphous carbon $[33,42]$. In addition, the values of $\mathrm{I}_{2 \mathrm{D}} / \mathrm{I}_{\mathrm{G}}$ obtained for partial pressures of methane higher than $14 \%$ indicate that the CNMs grown are composed by graphene-related materials, GRMs, of less than five graphene layers. In particular, for the experiment at $14.3 \%$ of $\mathrm{CH}_{4}\left(\mathrm{CH}_{4} / \mathrm{H}_{2}=1\right)$, both the $\mathrm{I}_{2 \mathrm{D}} / \mathrm{I}_{\mathrm{G}}$ ratio equal to 2.29 and the deconvolution of the $2 \mathrm{D}$ peak, see inset on Fig. 4a, clearly indicate the presence of monolayer and 2-layer graphene material $[57,58]$.

Therefore, the carburization step plays a key role not only on the catalytic performance of the segregated Fe NPs, but also and more relevant, on the quality of the CNMs obtained. Thus, a rapid carburization favours the carbon productivity, the Fe NPs stability and the selectivity to the formation of GRMs. On the contrary, a slow carburization, allows the catalyst fouling, hindering the carbon diffusion and favouring the formation of amorphous carbon.

Fig. 5 shows the transmission electron microscopy images obtained for the samples after reaction at different partial pressures of methane. In agreement with the previous results, at $\% \mathrm{CH}_{4}$ above $14 \%$, Fig. $5 \mathrm{~b}-\mathrm{d}$, the obtained CNMs were mainly composed by graphene layers, graphene-related materials (GRMs) and graphite nanoplatelets (GNPs) surrounding the metallic nanoparticles $[33,60]$. In agreement with previous results $[33,45,61]$, the formation of GRMs can be attributed to the exfoliation of the GNPs forming unstructured carbon flakes that evolve to form graphene and Few Layer Graphene (FLG). On the other hand, below the critical value of $14 \%$ of methane, Fig. $5 \mathrm{a}$, the production of carbonaceous nanomaterials is less selective to the formation of graphenic materials, favouring the accumulation of a less structured carbonaceous material, in agreement with the Raman and the kinetic results.

The effect of the partial pressure of hydrogen on the yield and the quality of the carbonaceous nanomaterials grown was evaluated changing the hydrogen concentration from $0 \%$ to $42.9 \%$, maintaining the methane content at $14.3 \%\left(\mathrm{~N}_{2}\right.$ as gas balance, total flow rate $700 \mathrm{~N}$ $\mathrm{mL} / \mathrm{min}$ ) and the reaction temperature at $950{ }^{\circ} \mathrm{C}$. At this $\% \mathrm{CH}_{4}$ were obtained GRMs with the best $\mathrm{I}_{\mathrm{G}} / \mathrm{I}_{\mathrm{D}}$ ratio, Fig. 4.

Fig. 3b shows the experimental and fitted curves of the evolution along time of carbon content (left) and reaction rate (right) at different $\% \mathrm{H}_{2}$. In this case, on the interval studied, the influence of the hydrogen concentration on the feed is less important than that observed for the methane, Fig. 3a, and the average productivity obtained in all the cases is between 0.062 and $0.077 \mathrm{gC} / \mathrm{g}_{\text {foam }} \mathrm{min}$, see Table 3 . In any case, hydrogen molecules also play a multiple role in the reaction mechanism. Thus, hydrogen competes with methane for the active site on the bare surface of the Fe NPs, it is also able to gasify part of the amorphous carbon formed on the metallic surface, recovering part of the activity of the Fe NPs rate $[33,42,45]$. Therefore, the dynamics of the carburization stage is also tuned by the hydrogen content. In this regard, in Fig. 3b (right) it can be seen that the maximum reaction rate, which determines the duration of the induction period, is affected by the $\% \mathrm{H}_{2}$. At higher hydrogen contents, the duration of the induction period is larger and the maximum reaction rate decreases. In these conditions of a hydrogen enriched atmosphere, the competence of $\mathrm{H}_{2}$ with the $\mathrm{CH}_{4}$ molecules slows dawn the carburization step and therefore the reaction rate and also the deactivation rate [33].

Regarding the application of the kinetic model, the fitting obtained again was excellent in all cases as can be seen on Table 3 . The evolution of the parameters with the $\mathrm{H}_{2}$ content is in agreement with the previous discussion. The expansion of the induction period with the $\% \mathrm{H}_{2}$ is explained by the model decreasing $\psi_{S}$ and increasing $K_{S}$. In fact, the huge values of $\psi_{S}$ at low $\mathrm{H}_{2}$ contents, Table 3 , or at high $\mathrm{CH}_{4}$ concentrations, Table 2, indeed means that the carburization is very fast, and above of certain value, it can be considered as instantaneous and the model can be simplified assuming from the beginning of the reaction 

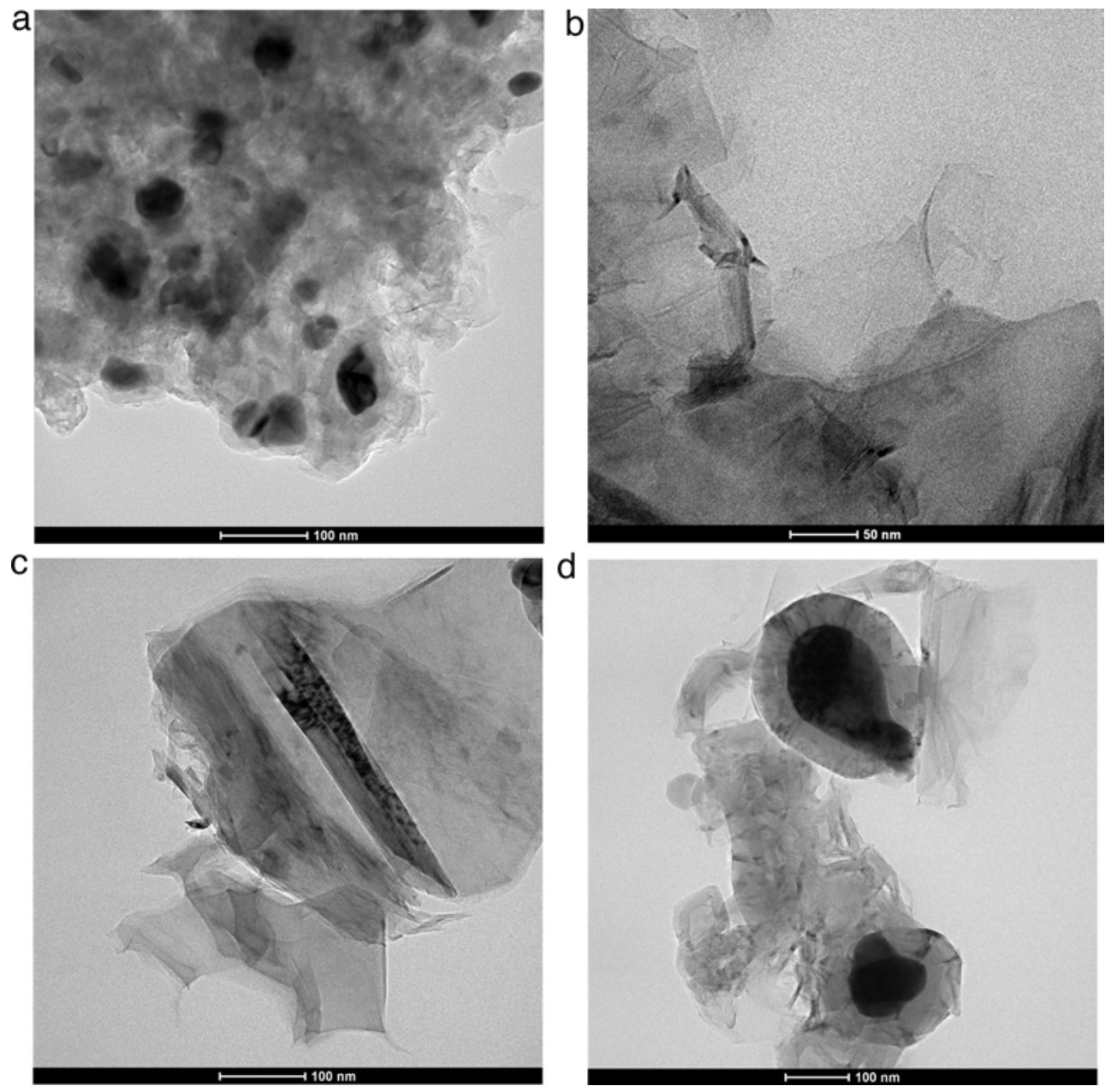

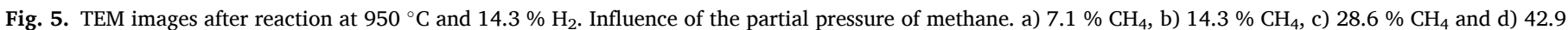
$\% \mathrm{CH}_{4}$.

Table 3

Effect of the partial pressure of hydrogen over the kinetic parameters $j_{C O}, K_{s}, \psi_{S}, \psi_{d}$, and $\psi_{r}$.

\begin{tabular}{|c|c|c|c|c|c|c|}
\hline$\% \mathrm{H}_{2}$ & $\mathrm{j}_{\mathrm{C} 0} \cdot 10^{3}\left(\mathrm{~g}_{\mathrm{C}} / \mathrm{g}_{\text {foam }} \min \right.$ & $\mathrm{K}_{\mathrm{S}}(-)$ & $\Psi_{\mathrm{S}} \cdot 10^{2}\left(\mathrm{~min}^{-1}\right)$ & $\Psi_{\mathrm{d}} \cdot 10^{2}\left(\mathrm{~min}^{-1}\right)$ & $\Psi_{\mathrm{r}} \cdot 10^{2}\left(\min ^{-1}\right)$ & Average Productivity $10^{2}\left(g_{C} / g_{\text {foam.h }}\right)$ \\
\hline 0 & $5.2 \pm 0.012$ & 0.00003 & 60340 & $9.25 \pm 0.04$ & $1.68 \pm 0.004$ & 6.80 \\
\hline 14.3 & $5.1 \pm 0.014$ & 0.0005 & 60340 & $9.25 \pm 0.04$ & $1.68 \pm 0.004$ & 6.57 \\
\hline 28.6 & $42.2 \pm 1.3$ & $0.0019 \pm 0.098$ & $4.07 \pm 0.17$ & $14.77 \pm 0.19$ & $0.36 \pm 0.01$ & 7.71 \\
\hline 42.9 & $8.8 \pm 0.20$ & $5.562 \pm 0.923$ & $12.02 \pm 0.85$ & $14.77 \pm 0.19$ & $1.46 \pm 0.02$ & 6.20 \\
\hline
\end{tabular}

that $\theta_{S}=1$.

With respect to the influence of the partial pressure of hydrogen on the quality of the CNMs grown, Raman spectra showed in Fig. 4 indicate that for these selected operating conditions, the materials obtained are mainly composed by graphene-related materials (mainly $1-4$ layers of graphene) $[57,58]$. In addition, it is observed that the increment in the hydrogen concentration causes a slight augment in the intensity of the D band, fact associated to the formation of shorter graphene-related materials that cause an increase in the density of the edge defects, [33,60, 61], as is confirmed by TEM, Fig. 6. In addition, the graphite nanolayers surrounding the metallic nanoparticles was also detected by TEM characterization (not showed), in accordance with the formation mechanism of these graphene-related materials.

\subsubsection{Influence of the reaction temperature}

The results showed in the previous section indicated that the productivity and type of carbonaceous nanomaterial grown depends on the duration of the carburization step. Temperature is an operational variable that has a great influence on diffusivity and therefore on the reaction rate. The effect of the reaction temperature was evaluated in the interval from $800{ }^{\circ} \mathrm{C}$ to $950{ }^{\circ} \mathrm{C}$, using a feed gas composition of $14.3 \%$ $\mathrm{CH}_{4}: 14.3 \% \mathrm{H}_{2}: 71.4 \% \mathrm{~N}_{2}$. These operating conditions were selected in order to optimize the selectivity to GRMs. Nevertheless, given that at these conditions the carburization step is very rapid, the apparent activation energies calculated are related to the diffusion-precipitation step, $j_{C 0}$, and to deactivation-regeneration one, $\psi_{d}$ and $\psi_{r}$. The values of $\psi_{S}$ and $K_{S}$ are fixed according to previous results presented in Tables 2 and 3. However, further studies are being developed by our group in order to investigate with more detail the effect of the reaction temperature on the carburization step.

The results of carbon concentration and reaction rate, including the model fittings, are presented on Fig. 7. As expected, the increase in reaction temperature, augments the average productivity of the foam, and also the initial carbon growth rate $[33,62]$. The maximum carbon productivity, $0.066 \mathrm{gC} / \mathrm{g}_{\text {foam }} \mathrm{h}$, is attained at $950{ }^{\circ} \mathrm{C}$. At high temperatures, carbon diffusivity through the metallic nanoparticles is also boosted and 

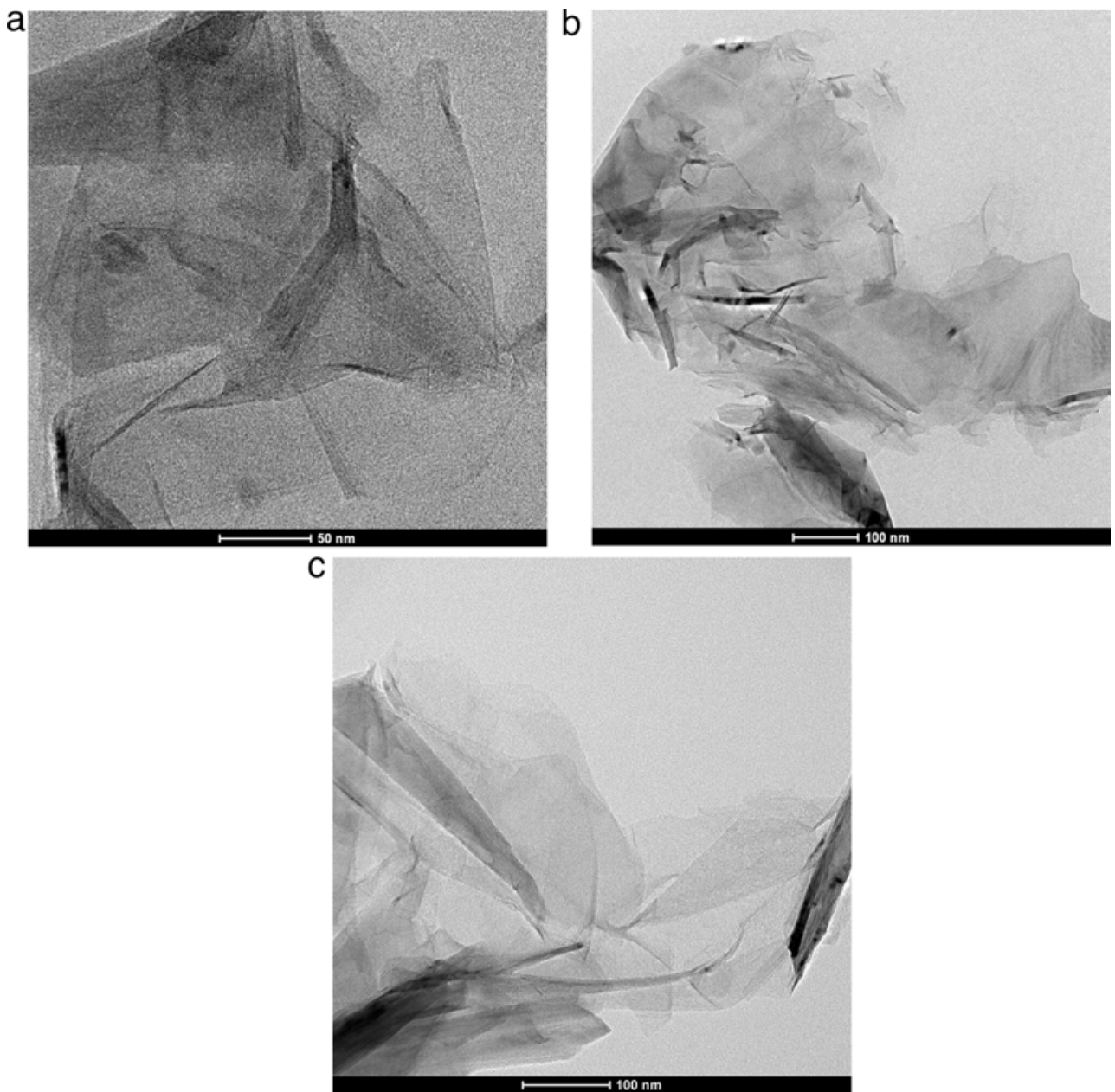

Fig. 6. TEM images after reaction at $950{ }^{\circ} \mathrm{C}$ and $14.3 \% \mathrm{CH}_{4}$. Influence of the partial pressure of hydrogen. a) $0 \% \mathrm{H}_{2}$, b) $14.3 \% \mathrm{H}_{2}$, c) $42.9 \% \mathrm{H}_{2}$.
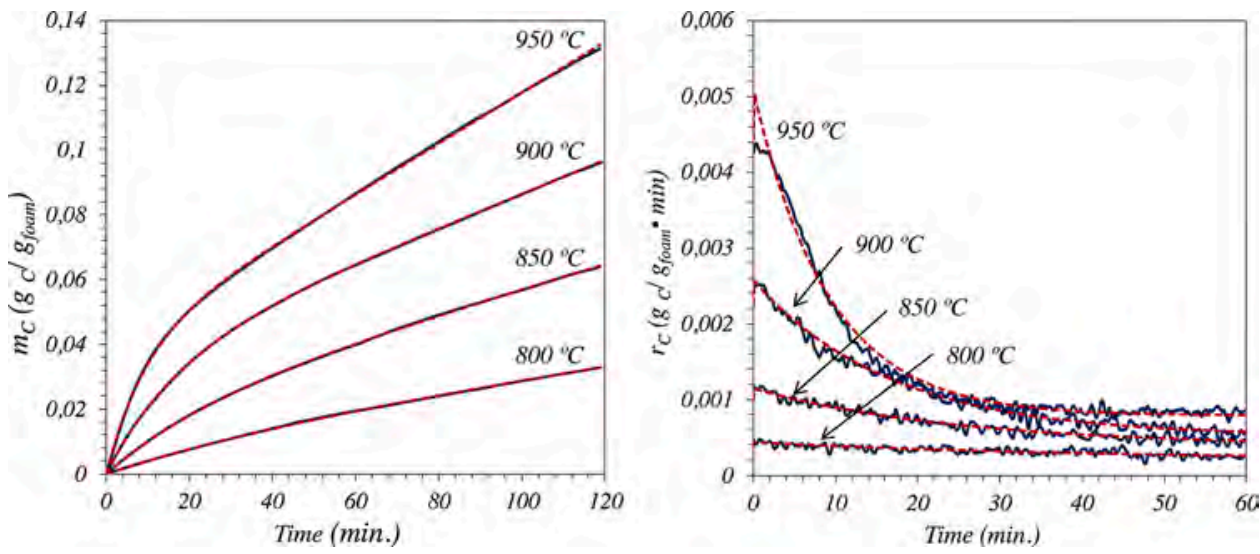

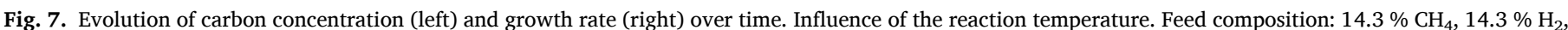

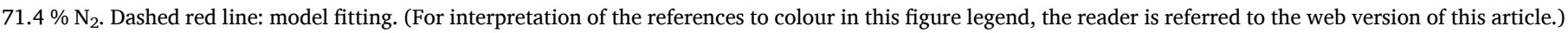

therefore the carbon precipitation rate at the metal-support interface is also improved. However, the deactivation of the Fe NPs is also favoured at these conditions.

The evolution of the kinetic parameters shown in Table 4 is a direct consequence of the above considerations. These values allow to calculate the apparent activation energies for the relevant parameters in this case: $j_{C O}, \psi_{d}, \psi_{r}$, see Fig. 8 . These $E_{\text {Aapp }}$ are $180 \mathrm{~kJ} / \mathrm{mol}$ for $j_{C 0}, 144 \mathrm{~kJ} /$ mol for $\psi_{d}$ and $28 \mathrm{~kJ} / \mathrm{mol}$ for $\psi_{r}$., which are in the interval of the values published, 80-235 $\mathrm{kJ} / \mathrm{mol}$ for $j_{C O}$ and $45-243 \mathrm{~kJ} / \mathrm{mol}$ for $\psi_{d}[33,42,45$,
56]. On the other hand, the $E_{\text {Aapp }}$ estimated for $\psi_{r}$ is indicating some diffusional control on this step probably caused by the CMN formed at these conditions [33].

The XRD patterns of the samples after reaction at temperatures increasing from $800{ }^{\circ} \mathrm{C}$ to $950{ }^{\circ} \mathrm{C}$, Fig. $2 \mathrm{~b}$, show an increase of the $\mathrm{Fe}_{3} \mathrm{C}$ and $\mathrm{C}$ signals and a decrease of the $\mathrm{Fe}_{2} \mathrm{O}_{3}$, becoming this phase negligible above $900{ }^{\circ} \mathrm{C}$. The formation of the iron carbide phase is enhanced by the high rates of carburization and diffusion of the carbon atoms attained at these conditions. The carbon precipitation rate at the metal- 
Table 4

Effect of the reaction temperature over the kinetic parameters $j_{C O}, K_{s}, \psi_{S}, \psi_{d}$, and $\psi_{r}$.

\begin{tabular}{|c|c|c|c|c|c|c|}
\hline Temp. $\left({ }^{\circ} \mathrm{C}\right)$ & $\mathrm{j}_{\mathrm{C} 0} \cdot 10^{3}\left(\mathrm{~g}_{\mathrm{C}} / \mathrm{g}_{\text {foam }} \min \right.$ & $\mathrm{K}_{\mathrm{S}}(-)$ & $\Psi_{\mathrm{S}}\left(\min ^{-1}\right)$ & $\Psi_{\mathrm{d}} \cdot 10^{2}\left(\min ^{-1}\right)$ & $\Psi_{\mathrm{r}} \cdot 10^{2}\left(\min ^{-1}\right)$ & Average Productivity $\cdot 10^{2}\left(\mathrm{~g}_{\mathrm{C}} / \mathrm{g}_{\text {foam.h }}\right)$ \\
\hline 800 & $0.4 \pm 0.016$ & 0.0005 & 603.0 & $1.26 \pm 0.01$ & $1.06 \pm 0.02$ & 1.65 \\
\hline 850 & $1.1 \pm 0.013$ & 0.0005 & 603.0 & $2.65 \pm 0.01$ & $1.34 \pm 0.01$ & 3.20 \\
\hline 900 & $2.6 \pm 0.015$ & 0.0005 & 603.4 & $4.79 \pm 0.01$ & $1.22 \pm 0.002$ & 4.82 \\
\hline 950 & $5.1 \pm 0.012$ & 0.0005 & 603.4 & $9.25 \pm 0.04$ & $1.68 \pm 0.004$ & 6.57 \\
\hline
\end{tabular}

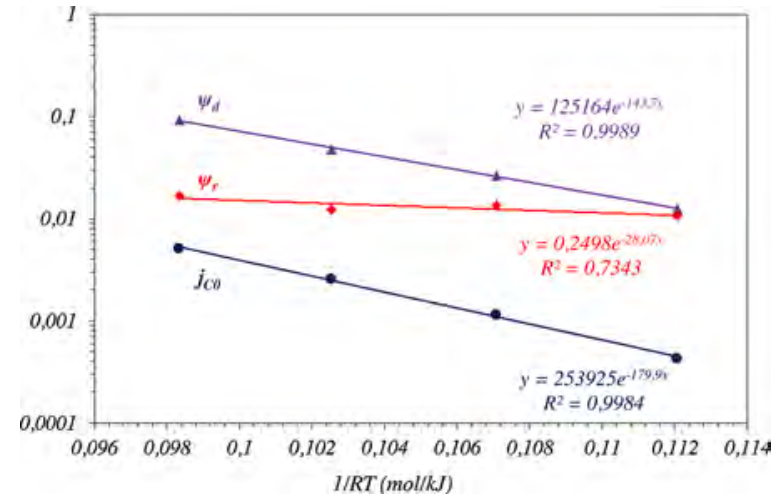

Fig. 8. Arrhenius plot of the kinetic parameters $j_{C O}, \psi_{d}$, and $\psi_{r}$.

support interface is also improved and therefore the productivity of the foam is favoured [33].

The effect of the reaction temperature on the quality of the CNMs grown was studied by Raman spectroscopy and the results are shown in Fig. 9. In this case, the ratio $I_{G} / I_{D}$ increases with the reaction temperature, which favours a lower presence of defects on the CNMs obtained. Therefore, the crystallinity of the graphitic domains present in these CNMs is higher at high temperatures. Interestingly, the 2D band intensity became higher above $900{ }^{\circ} \mathrm{C}$, revealing the transition in the nature of the CNMs grown. The values of the $\mathrm{I}_{2 \mathrm{D}} / \mathrm{I}_{\mathrm{G}}$ obtained above 900 ${ }^{\circ} \mathrm{C}(>0.7)$ indicate that the CNMs are mainly composed by graphene and Few-Layer Graphene materials (FLGs) with less than five layers of graphene $[57,58]$. Transition electron microscopy results, shown in Fig. 10, also confirms the change on the selectivity at around $900{ }^{\circ} \mathrm{C}$. Thus, below this temperature, Fig. 10a and b, CNTs are the more abundant forms, while above $900{ }^{\circ} \mathrm{C}$, the products observed are FLGs and even separate graphene layers. The mechanism of formation of GRMs involves the exfoliation of flakes from the graphite nanoplatelets formed in the conditions of high temperature, see Fig. 5d [33,45,61].

These results are in agreement with the results obtained by other authors using these type of metallic substrates to synthetize graphene related materials by light hydrocarbon decomposition at high

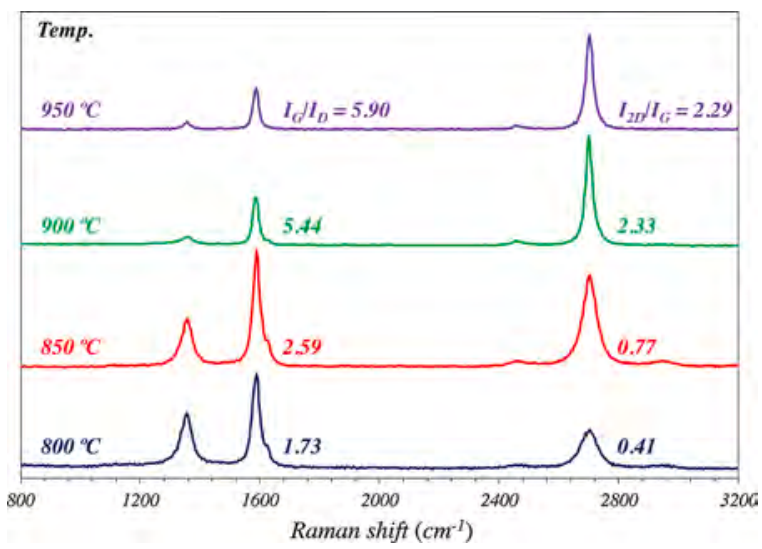

Fig. 9. Raman spectra of stainless steel foam after reaction at different temperatures. Feed composition: $14.3 \% \mathrm{CH}_{4}, 14.3 \% \mathrm{H}_{2}, 71.4 \% \mathrm{~N}_{2}$. temperatures. Thus. Ruammaitree et al. [63], working with Stainless Steel foils (SS304) obtain good quality graphene related materials by decomposition of methane at temperatures around $1000{ }^{\circ} \mathrm{C}$. Similar results, has been also obtained with stainless steel substrate using other carbon sources instead methane [64,65].

\section{Conclusions}

In this work, it has been obtained that the stainless steel foams are able to produce selectively carbonaceous nanomaterials via catalytic decomposition of methane at temperatures ranged from 800 to $950{ }^{\circ} \mathrm{C}$. The main active phases for the reaction are the Fe nanoparticles segregated from the stainless-steel after the activation (oxidation-reduction) stage of the foam. The proper selection of feed composition and reaction temperature allowed us to maximize the productivity, stability and selectivity to GRMs. The maximum carbon productivity, $0.116 \mathrm{~g} / \mathrm{g}_{\text {foam }}$ h was reached at $950{ }^{\circ} \mathrm{C}$ using a $\mathrm{CH}_{4} / \mathrm{H}_{2}$ ratio of 3/1 $\left(42.9 \% \mathrm{CH}_{4}: 14.3 \%\right.$ $\mathrm{H}_{2}$ ).

The kinetic results indicate that the increase in reaction temperature, augments the average productivity of the foam, and also the initial carbon growth rate. At high temperatures, carbon diffusivity through the metallic nanoparticles is also boosted and therefore the carbon precipitation rate at the metal-support interface is also improved. However, the deactivation of the Fe nanoparticles is also favoured at these conditions.

The increase of methane content in the feed boosts the reaction rate increasing almost linearly the average productivity of the sample. The higher carburization rates of the exposed surface of the Fe nanoparticles attained increase the number of carbon atoms dissolved in these NPs, favouring the migration and finally the carbon precipitation at the metal-support interface. The duration of the carburization step determine the length of the initial induction period characterized by a low rate of carbon formation, which is also affected by the hydrogen content. In a hydrogen rich atmosphere, the competence of $\mathrm{H}_{2}$ with the $\mathrm{CH}_{4}$ molecules slows dawn the carburization and consequently the reaction rat, but also the deactivation.

The carburization step plays a key role not only on the catalytic performance of the segregated Fe nanoparticles, but also and more relevant, on the quality of the CNMs obtained. Thus, a rapid carburization favours the carbon productivity, the Fe NPs stability and the selectivity to the formation of GRMs. On the contrary, a slow carburization, allows the catalyst fouling, hindering the carbon diffusion and favouring the formation of amorphous carbon. The parameters of the kinetic model developed are directly related to the relevant stages of the process. The balance among these sequential stages determines the overall performance of the activated foam. In conditions of rapid carburization of the Fe NPs ( $\mathrm{p}_{\mathrm{CH} 4}>14 \%$ ), the productivity to CNMs is favoured, avoiding an initial deactivation of the active sites by fouling with amorphous carbon. After a rapid carburization, the selectivity to the different CNMs is governed by the ratio $\mathrm{CH}_{4} / \mathrm{H}_{2}$, and mainly by the temperature. Thus, the formation of GRMs, mainly graphene and Few Layer Graphene (FLG), is favoured at temperatures above $900{ }^{\circ} \mathrm{C}$. At lower temperatures, carbon nanotubes are formed.

\section{Funding}

Funding was received for this work. 

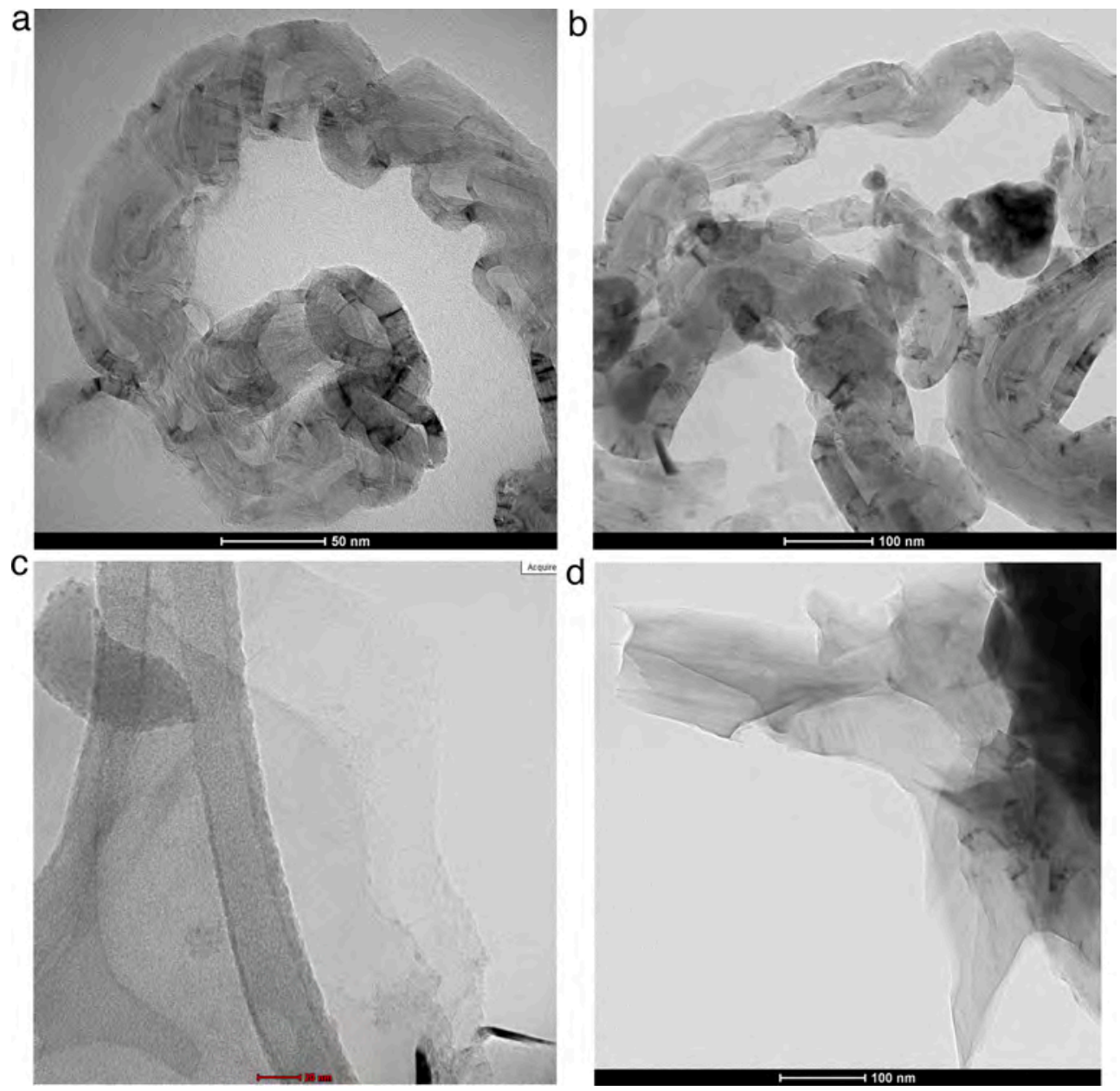

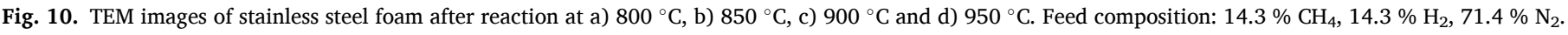

\section{Intellectual property}

We confirm that we have given due consideration to the protection of intellectual property associated with this work and that there are no impediments to publication, including the timing of publication, with respect to intellectual property. In so doing we confirm that we have followed the regulations of our institutions concerning intellectual property.

\section{Authorship}

We confirm that the manuscript has been read and approved by all named authors.

We confirm that the order of authors listed in the manuscript has been approved by all named authors.

\section{Contact with the editorial office}

This author submitted this manuscript using his/her account in editorial submission system.

\section{CRediT authorship contribution statement}

F. Cazaña: Writing - original draft, Investigation, Methodology, Data curation. N. Latorre: Conceptualization, Investigation, Methodology, Data curation, Supervision. P. Tarifa: Investigation, Methodology, Data curation. C.J. Royo: Investigation, Methodology, Data curation. V. Sebastián: Investigation. E. Romeo: Conceptualization, Investigation,
Methodology, Data curation, Supervision. M.A. Centeno: Methodology, Writing - review \& editing, Funding acquisition. A. Monzón: Writing original draft, Writing - review \& editing, Methodology, Supervision, Project administration, Funding acquisition, Supervision.

\section{Declaration of Competing Interest}

The authors report no declarations of interest.

\section{Acknowledgements}

The authors acknowledge financial support from MICINN (Madrid, Spain) FEDER, Project ENE2017-82451-C3. P. Tarifa acknowledges the grant of MICINN (Ref.: BES-2014-069010). Authors also acknowledge the use of "Servicio General de Apoyo a la Investigación-SAI", Universidad de Zaragoza.

\section{References}

[1] K.S. Novoselov, Rev. Mod. Phys. 83 (2011) 837-849.

[2] W.W. Liu, S.P. Chai, A.R. Mohamed, U. Hashim, J. Ind. Eng. Chem. 20 (4) (2014) 1171-1185.

[3] J.A.R. Siamaki, A.E.R.S. Khder, V. Abdelsayed, M.S. El-Shall, B.F. Gupton, J. Catal. 279 (2011) 1-11.

[4] J. Shin, J.T. Kim, Nanotechnology 26 (2015), 365201.

[5] M.J. Nine, M.A. Cole, D.N.H. Tran, D. Losic, J. Mater. Chem. A 3 (2015) 12580-12602.

[6] T. Han, A. Nag, S. Chandra-Mukhopadhyay, Y. Xu, Sens. Actuator A Phys. 291 (2019) 107-143.

[7] V.R. Raphey, T.K. Henna, K.P. Nivitha, P. Mufeedha, C. Sabu, K. Pramod, Mater. Sci. Eng. C 100 (2019) 616-630. 
[8] S. Ullah, Int. J. Hydrogen Energy 45 (2020) 4653-4672.

[9] X.K. Kong, C.L. Chen, Q.W. Chen, Chem. Soc. Rev. 43 (2014) 2841-2857.

[10] D.S. Su, S. Perathoner, G. Centi, Chem. Rev. 113 (2013) 5782-5816.

[11] C. Mu, K. Huang, T. Cheng, H. Wang, H. Yu, F. Peng, Chem. Eng. J. 306 (2016) $806-815$.

[12] A. Cybulski, J.A. Moulijn, Structured Catalysts and Reactors, second ed., Taylor and Francis, New York, 2006.

[13] P. Ávila, M. Montes, E.E. Miró, Chem. Eng. J. 109 (1-3) (2005) 11-36.

[14] G. Pauletto, A. Vaccari, G. Groppi, L. Bricaud, P. Benito, D.C. Boffito, J.A. Lercher, G.S. Patience, Chem. Rev. 120 (15) (2020) 7516-7550.

[15] E. García-Bordejé, Y. Liu, D. Sheng Su, C. Pham-Huu, J. Mater. Chem. A 5 (2017) 22408-22441.

[16] L. Giani, G. Groppi, E. Tronconi, Ind. Eng. Chem. Res. 44 (14) (2005) 4993-5002

[17] E. Reichelt, M.P. Heddrich, M. Jahn, A. Michaelis, Appl. Catal. A Gen. 476 (2014) 78-90.

[18] Y. Matatov-Meytal, M. Sheintuch, Appl. Catal. A Gen. 231 (2002) 1-16.

[19] J.K. Chinthaginjala, K. Seshan, L. Lefferts, Ind. Eng. Chem. Res. 46 (2007) 3968-3978.

[20] J. Amadou, D. Begin, P. Nguyen, J.P. Tessonnier, T. Dintzer, E. Vanhaecke, M. J. Ledoux, C. Pham-Huu, Carbon 44 (12) (2006) 2587-2592.

[21] T. Kato, R. Hatakeyama, ACS Nano 4 (12) (2010) 7395-7400.

[22] K. Hata, D.N. Futaba, K. Mizuno, T. Namai, M. Yumura, S. Iijima, Science 306 (5700) (2004) 1362-1364.

[23] C.E. Baddour, D.C. Upham, J.L. Meunier, Carbon 48 (9) (2010) 2652-2656.

[24] N.A. Jarrah, J.G. van Ommen, L. Lefferts, J. Catal. 239 (2006) 460-469.

[25] L.Z. Gao, L. Kiwi-Minsker, A. Renken, Surf. Coat. Technol. 202 (2008) 3029-3042.

[26] V. Martínez-Hansen, N. Latorre, C. Royo, E. Romeo, E. García-Bordejé, A. Monzón, Catal. Today 147S (2009) S71-S75.

[27] C.E. Baddour, C. Briens, Int. J. Chem. React. Eng. 3 (1) (2005) R3.

[28] M. Kumar, Y. Ando, J. Nanosci. Nanotechnol. 10 (6) (2010) 3739-3758.

[29] Q. Zhang, J.Q. Huang, M.Q. Zhao, W.Z. Qian, F. Wei, ChemSusChem 4 (2011) 864-889.

[30] R. Brukh, S. Mitra, Chem. Phys. Lett. 424 (1-3) (2006) 126-132.

[31] D. Chen, K.O. Christensen, E. Ochoa-Fernández, Z. Yu, B. Tøtdal, N. Latorre, A. Monzón, A. Holmen, J. Catal. 229 (2005) 82-96.

[32] N. Latorre, E. Romeo, F. Cazaña, T. Ubieto, C. Royo, J.I. Villacampa, A. Monzón, J. Phys. Chem. C 114 (2010) 4773-4782.

[33] F. Cazaña, N. Latorre, P. Tarifa, J. Labarta, E. Romeo, A. Monzón, Catal. Today 299 (2018) 67-79.

[34] W. Zhou, Z. Han, J. Wang, Y. Zhang, Z. Jin, X. Sun, Y. Zhang, C. Yan, Y. Li, Nano Lett. 6 (2006) 2987-2990.

[35] M.A. Pasha, A. Shafiekhani, M.A. Vesaghi, Appl. Surf. Sci. 256 (2009) 1365-1371.

[36] J.M. Aguiar-Hualde, Y. Magnin, H. Amara, C. Bichara, Carbon 120 (2017) $226-232$.

[37] A.E. Awadallah, A.A. Aboul-Enein, M.A. Azab, Y.K. Abdel-Monem, Fullerenes Nanotubes Carbon Nanostruct. 25 (2017) 256-264.
[38] C.E. Baddour, F. Fadlallah, D. Nasuhoglu, R. Mitra, L. Vandsburger, J.L. Meunier, Carbon 47 (1) (2009) 313-318.

[39] S. Pacheco Benito, L. Lefferts, Carbon 48 (2010) 2862-2872.

[40] J.I. Villacampa, C. Royo, E. Romeo, J.A. Montoya, P. del Angel, A. Monzón, Appl. Catal. A Gen. 252 (2003) 363-383.

[41] M. Azuara, N. Latorre, J.I. Villacampa, V. Sebastian, F. Cazaña, E. Romeo, A. Monzón, Front. Energy Res. 7 (34) (2019).

[42] N. Latorre, E. Romeo, J.I. Villacampa, F. Cazaña, C. Royo, A. Monzón, Catal. Today 154 (2010) 217-223.

[43] P. Nikolaidis, A. Poullikkas, Renew. Sustain. Energy Rev. 67 (2017) 597-611.

[44] N. Latorre, F. Cazaña, V. Sebastián, C. Royo, E. Romeo, M.A. Centeno, A. Monzón, Catal. Today 273 (2016) 41-49.

[45] N. Latorre, F. Cazaña, V. Sebastián, C. Royo, E. Romeo, A. Monzón, Int. J. Chem. React. Eng. 15 (2) (2017) 20170121.

[46] A. Monzón, G. Lolli, S. Cosma, M. Sayed-Ali, D.E. Resasco, J. Nanosci. Nanotechnol. 8 (2008) 6141-6152.

[47] I. Alstrup, J. Catal. 109 (1988) 241-251.

[48] C. Zhang, S. Pisana, C.T. Wirth, A. Parvez, C. Ducati, S. Hofmann, J. Robertson, Diam. Relat. Mater. 17 (2008) 1447-1451.

[49] A. Borgna, T.F. Garetto, A. Monzón, C.R. Apesteguía, J. Catal. 146 (1) (1994) 69-81.

[50] C.I. Meyer, A.J. Marchi, A. Monzon, T.F. Garetto, Appl. Catal. A Gen. 367 (2009) $122-129$.

[51] A. Monzón, E. Romeo, A. Borgna, Chem. Eng. J. 94 (2003) 19-28.

[52] S. Rimaz, L. Chen, A. Monzón, S. Kawi, A. Borgna, Chem. Eng. J. 405 (2021), 126656.

[53] E.J. Ward, Ecol. Model. 211 (2008) 1-10.

[54] A. Bautista, F. Velasco, M. Campos, M.E. Rabanal, J.M. Torralba, Oxid. Met. 59 (2003) 373-393.

[55] J. Li, E. Croiset, L. Ricardez-Sandoval, J. Catal. 326 (2015) 15-25.

[56] M.S. Dresselhaus, A. Jorio, M. Hofmann, G. Dresselhaus, R. Saito, Nano Lett. 10 (2010) 751-758.

[57] I. Calizo, I. Bejenari, M. Rahman, G. Liu, A.A. Balandin, J. Appl. Phys. 106 (2009), 043509.

[58] C. Cong, T. Yu, R. Saito, G.F. Dresselhaus, M.S. Dresselhaus, ACS Nano 5 (3) (2011) 1600-1605.

[59] A.C. Ferrari, D.M. Basko, Nat. Nanotechnol. 8 (2013) 235-246.

[60] S.M. Kim, L.P. Cary, B.A. Placidus, N.Z. Dmitri, H.H. Robert, B. Maruyama, E. A. Stach, J. Phys. Chem. Lett. 1 (2010) 918-922.

[61] A.K. Geim, Science 324 (2009) 1530-1534.

[62] C.J. Lee, J. Park, Y. Huh, J. Yong Lee, Chem. Phys. Lett. 343 (2001) 33-38.

[63] A. Ruammaitree, D. Phokharatkul, N. Nuntawong, A. Wisitsoraat, Surf. Rev. Lett. 25 (2018), 1840003.

[64] L.F. Dumée, L. He, Z. Wang, P. Sheath, J. Xiong, C. Feng, M.Y. Tan, F. She, M. Duke, S. Gray, A. Pacheco, P. Hodgson, M. Majumder, L. Kong, Carbon 87 (2015) 395-408.

[65] F. Liu, H. Zhang, H. Huang, Y. Yan, J. Hazard. Mater. 384 (2020), 121246. 